Publicação organizada pelo Programa de

Mestrado Profissional Stricto Sensu em

Engenharia Civil da Universidade São Judas

Volume 03 - Edição 01

Janeiro - Dezembro de 2020

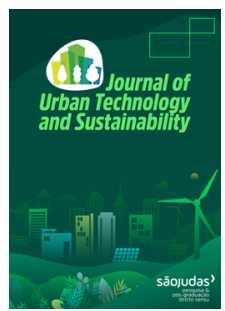

\title{
As cidades e o aquecimento global: desafios para o planejamento urbano, as engenharias e as ciências sociais e básicas
}

Renato L. S. Anellia,*

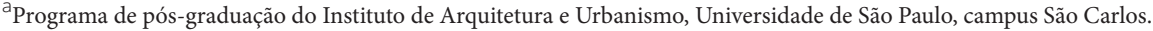

\section{Informações}

Recebido 7 Fevereiro 2020

Manuscrito revisado recebido 8 Abril 2020

Aceito 12 Abril 2020

Palavras-chave

Aquecimento global

Planejamento urbano

Mudanças climáticas

Sustentabilidade

\section{Resumo}

Este artigo tem como objetivo apresentar uma abordagem transdisciplinar para a relação entre as mudanças climáticas e as cidades. Parte do reconhecimento de que a atual forma da urbanização das grandes regiões metropolitanas é forte agente promotor do aquecimento global, ao mesmo tempo que constitui lócus da manifestação nociva dos efeitos dessas mudanças. A alteração dos regimes de chuva, com maior frequência e intensidade, da distribuição das precipitações e do fenômeno das ilhas de calor afetam em especial as áreas de assentamentos mais precários, onde a elevada vulnerabilidade social expõe gigantescos contingentes de pessoas a riscos constantes de inundação, deslizamentos, falta de água potável e saneamento básico, e doenças geradas pelo calor excessivo. A busca por sustentabilidade ambiental envolve essa dimensão social, exigindo das ciências e das técnicas um esforço transdisciplinar para ações integradas que possa fazer frente ao desafio ético da desigualdade social entre os afetados pelos efeitos nocivos das mudanças climáticas.

\section{Cities and global warming: challenges for urban planning, engineering and social and basic sciences}

\section{Article info \\ Received 7 February 2020 \\ Received in revised form 8 April 2020 \\ Accepted 12 April 2020}

\section{Keywords}

Global warming

Urban planning

Climate change

Sustainability

\begin{abstract}
This article aims to present a transdisciplinary approach to the relationship between climate change and cities. Part of the recognition that the current form of urbanization in large metropolitan regions is a strong agent that promotes global warming, at the same time that it is the locus of the harmful manifestation of the effects of these changes. The change in rainfall patterns, with greater frequency and intensity, in the distribution of rainfall and the phenomenon of heat islands, particularly affects the most precarious settlement areas, where high social vulnerability exposes gigantic contingents of people to constant flood risks, landslides, lack of drinking water and basic sanitation, and diseases caused by excessive heat. The search for environmental sustainability involves this social dimension, requiring from sciences and techniques a transdisciplinary effort for integrated actions that can face the ethical challenge of social inequality among those affected by the harmful effects of climate change.
\end{abstract}

\section{Ciudades y el calentamiento global: desafios para el urbanismo, las ingenierías y las ciéncias sociales y básicas}

\section{Información}

Recibido 7 Febrero 2020

Manuscrito revisado recibido 8 Abril 2020

Aceptado 12 Abril 2020

\section{Palabras clave}

Calentamiento global

Urbanismo

Cambios climáticos

Sostenibilidad

\section{Resumen}

Este artículo tiene como objetivo presentar un enfoque transdisciplinario de la relación entre el cambio climático y las ciudades. Parte del reconocimiento de que la forma actual de urbanización en las grandes regiones metropolitanas es un fuerte agente que promueve el calentamiento global, al mismo tiempo que es el lugar de manifestación nociva de los efectos de estos cambios. El cambio en los patrones de lluvia, con mayor frecuencia e intensidad, en la distribución de las lluvias y el fenómeno de las islas de calor, afectan particularmente a las áreas de asentamiento más precarias, donde la alta vulnerabilidad social expone gigantes contingentes de personas a constantes riesgos de inundaciones. deslizamientos de tierra, falta de agua potable y saneamiento básico, y enfermedades causadas por el calor excesivo. La búsqueda de la sostenibilidad ambiental involucra esta dimensión social, requiriendo desde las ciencias y técnicas un esfuerzo transdisciplinario para acciones integradas que puedan enfrentar el desafío ético de la desigualdad social entre los afectados por los efectos nocivos del cambio climático.

\footnotetext{
* Autor correspondente em: Programa de pós-graduação em Arquitetura e Urbanismo, Universidade de São Paulo, campus São Carlos. 


\section{Mudanças climáticas antrópicas e os de- safios para o planejamento urbano}

A cidade de São Paulo foi implantada em um território constituído por densa rede hídrica que condiciona sua urbanização até os dias atuais. O território montanhoso gera uma enorme quantidade de córregos, que convergem para os rios Aricanduva, Pinheiros, Tamanduateí e Tietê, formando amplas planícies fluviais. Foi sobre essa complexa geomorfologia que se construiu o sistema viário estrutural, composto pelas avenidas marginais, nas principais planícies fluviais, alimentadas pela rede de avenidas de fundo de vale. Se essa prática já estava presente na primeira metade do século XX, no Plano de Avenidas de Prestes Maia, os planos subsequentes transformaram os talvegues, várzeas e fundos de vale em eixos de expansão da urbanização.

Travassos (2010) e Gronstein (2001) apontam a institucionalização dessa prática, transformada em política pública na década de 1970 com recursos federais e estaduais para canalização de córregos para a construção de ruas e avenidas. Ao mesmo tempo que ocultava o esgoto lançado sem tratamento no curso d'água, tornava viável a comercialização de áreas alagáveis, essenciais para que os ciclos dos rios não oferecessem riscos. Ao mesmo tempo que a retificação, canalização e tamponamento dos cursos d'água gerou espaço para a construção da cidade, edifícios e vias, estabeleceu vínculos permanente entre os fluxos das águas e o dos veículos.

A alteração dos regimes hídricos (SILVA DIAS, 2013), com a maior frequência de chuvas intensas, torna obsoleto os parâmetros de chuva de projeto consolidados pela engenharia de infraestrutura ao longo do século XX. Estudos recentes apresentam projeções alarmantes para o agravamento dos extremos de chuva, seca e calor na RMSP.

Considerando as médias entre 1971 e 2000, Resenzweig e Solecki (2018) preveem o cenário mostrado na tabela 1 para as próximas décadas. O forte crescimento da amplitude nos extremos positivos e negativos dos índices de precipitação agravarão violentamente a situação de enchentes, deslizamentos e secas em um prazo de vinte,
Tabela 1. Evolução das médias de temperatura e precipitação (RESENZWEIG; SOLECKI, 2018).

\begin{tabular}{ccc}
\hline Ano & Temperatura $\left({ }^{\circ} \mathbf{C}\right)$ & Chuva (\%) \\
\hline 2020 & $+0,9 a+1,7$ & $-31 a+43$ \\
2040 & $+1,7 a+3,6$ & $-32 a+58$ \\
2080 & $+2,1 a+6$ & $-38 a+81$ \\
\hline
\end{tabular}

quarenta e oitenta anos.

Projetadas de acordo com parâmetros de vazão cada vez mais ultrapassados pelas mudanças climáticas, os dispositivos de escoamento e retenção das águas pluviais não cumprem mais a função de evitar transbordamentos. Resulta assim em maior frequência e intensidade de inundações do sistema viário e das áreas edificadas lindeiras, com elevados danos às pessoas que moram, trabalham ou circulam nessas áreas. A insuficiência da infraestrutura é ainda mais grave nas regiões de ocupação informal e precária, onde são frequentes os deslizamentos de encostas devido às deficiências e/ou ausência de sistemas de drenagem superficial adequado.

Pesquisas sobre o clima em área urbana apontam que tais alterações em São Paulo são decorrentes de fatores antrópicos locais, tais como a forma da urbanização e as emissões de gases de efeito estufa por motores veiculares (NOBRE et al, 2011). Consideramos que tal combinação cria um desafio de caráter socioambiental, o de evitar os danos sociais causados pelos desequilíbrios ambientais. Para superá-lo é necessária a ação integrada nas áreas de planejamento e projeto urbano, engenharias de transportes, hidráulica, solos.

O Plano Diretor Estratégico PDE elaborado entre 2013 e 2014 foi a revisão do plano de 2002, conforme previsto pelo Estatuto da Cidade. O momento de sua elaboração coincide com as primeiras consolidações de estudos científicos que reconheceram os impactos das mudanças climáticas na Região Metropolitana de São Paulo - RMSP. Ao longo desta última década, intensificaram-se a frequência e a intensidade de eventos extremos como inundações, escassez de água potável, deslizamentos de terra e ilhas de calor. Em função do padrão de urbanização paulistano, a alteração do regime de chuvas provoca os três primeiros fenômenos - enchentes 


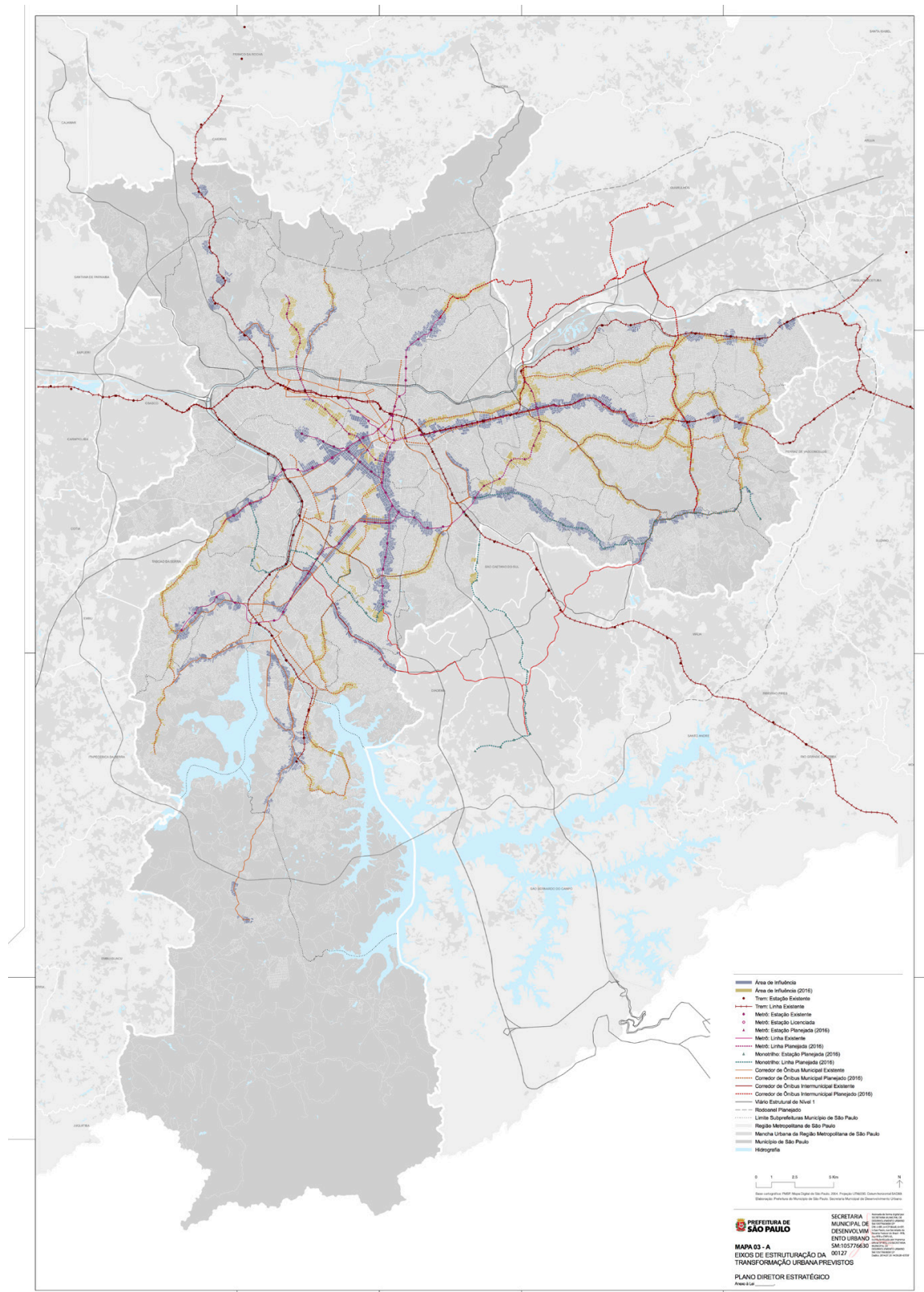

Fig. 1. Mapa Eixos de Estruturação da Transformação Urbana. Plano Diretor Estratégico de 2014. Gestão Urbana.

e deslizamentos em áreas urbanizadas combinada com a falta de água potável. A formação de ilhas de calor decorre de combinação mais complexa, entre o padrão de mobilidade baseado em veículos automotivos geradores de Gases de Efeito Estufa, a necessidade de grandes deslocamentos diários e a predominância de superfícies reflexivas.

O PDE 2014 estabelece várias diretrizes para a redução desses fatores, tais como ampliar o uso de transporte público, reduzir a necessidade de deslocamentos pendulares diários entre casa e trabalho e conter a expansão horizontal da área urbana.

Um dos principais pilares do Plano Diretor Estratégico de São Paulo foi um quadro de instrumentos urbanísticos apoiado na rede de infraestrutura de transporte de alta capacidade, existente e planejada. Corredores de ônibus e linhas de metrô e trens configuraram a malha dos Eixos de Estruturação da Transformação Urbana - EETU, instrumento do PDE que visa a distribuição linear do adensamento, formando faixas verticalizadas pelo território urbano. Pretendeu-se evitar tanto o crescimento espraiado horizontal, quanto a concentração excessiva no centro expandido.

No que se refere à mobilidade urbana, os EETU tiveram como objetivo estimular a substituição de viagens de automóveis pelas de transporte público de alta e média capacidade, oferecendo mais moradia e emprego a distância de caminhada dos pontos de embarque e desembarque. 0 


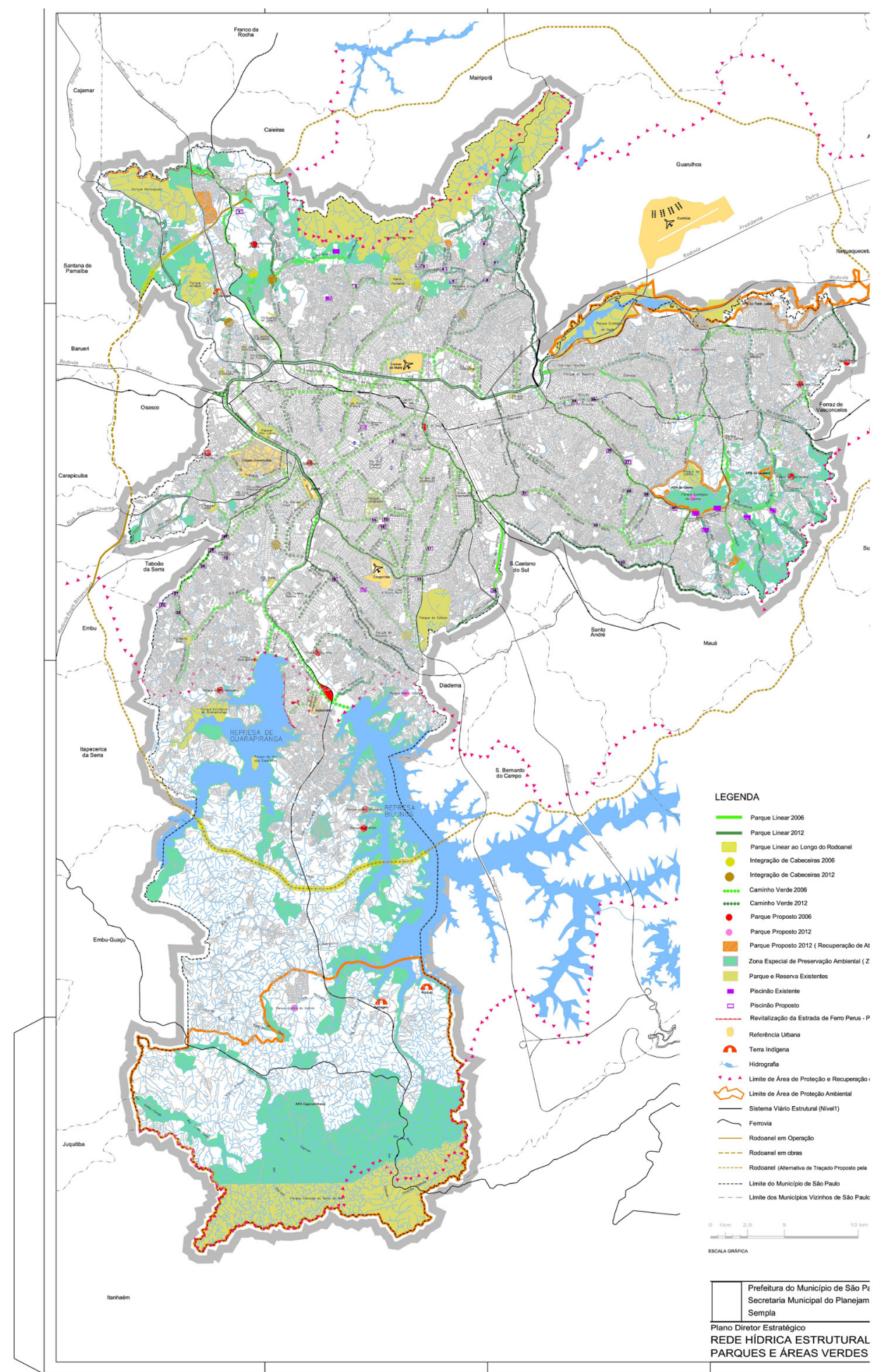

Fig. 2. Mapa de Rede Hídrica Estrutural. Plano Diretor Estratégico de 2002. Gestão Urbana.

incentivo ao uso misto das novas edificações nos EETU visa reduzir a própria necessidade de grandes deslocamentos diários, pois distribui mais homogeneamente as atividades geradoras de emprego e as moradias. Enfrenta assim duas condições que degradam as condições ambientais de São Paulo.

Já apontamos em outras ocasiões os riscos de agravamento das enchentes decorrentes da associação entre o sistema viário estrutural que coincide com a rede hidrográfica com os adensamentos lindeiros aos corredores de ônibus.

\section{Planejamento e gestão da drenagem urbana}

Para a evitar as enchentes mais graves, as estratégias do PDE 2014 foram divididas em duas frentes. Na escala do lote, estabeleceu a cota ambiental, que premia quem utiliza alguns 


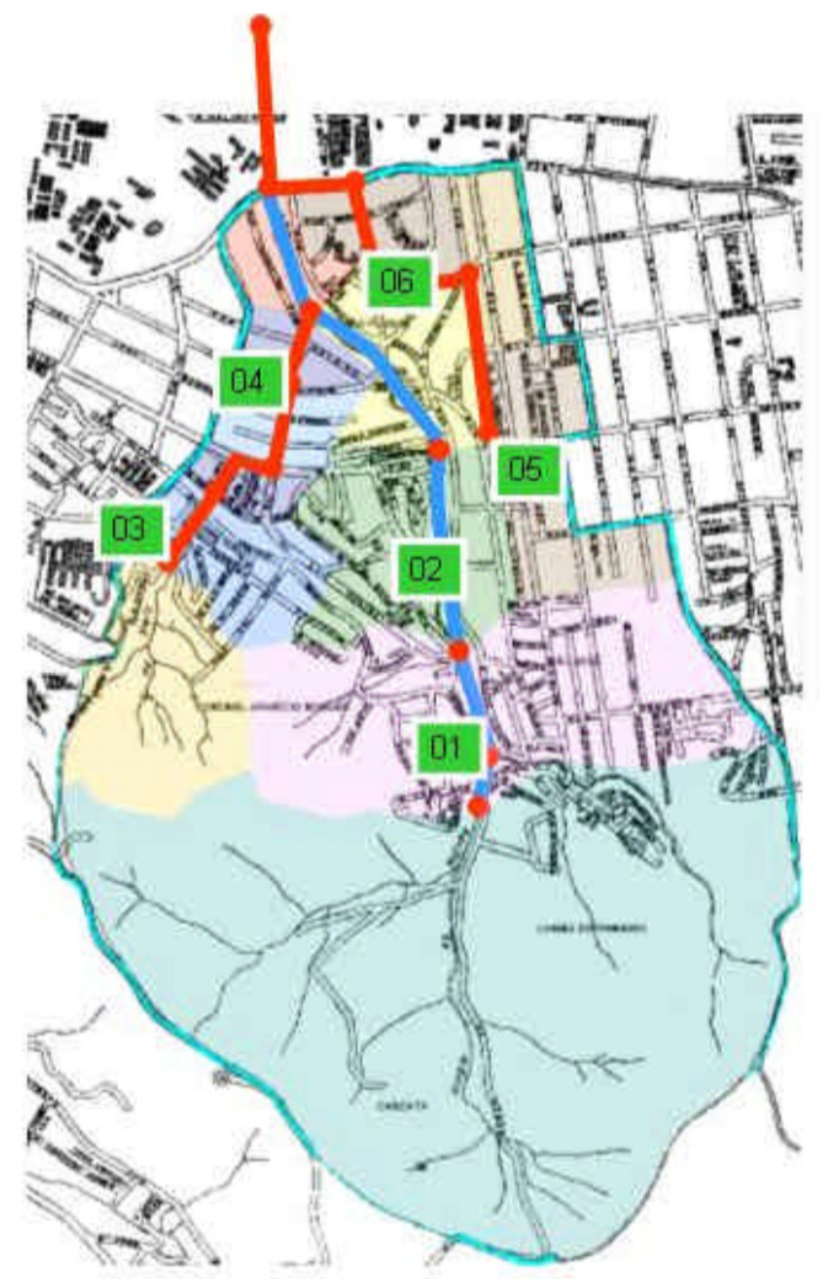

Fig. 3. Mapa de dispositivos de contenção de enchentes na Bacia do Arroio do Moinho, Porto Alegre (SOUZA et al, 2012).

dispositivos de retenção e absorção das águas pluviais no empreendimento. Na escala territorial, definiu um Sistema de Saneamento Ambiental que integra abastecimento de água, esgotamento sanitário, drenagem e resíduos sólidos, prevendo um Plano Diretor de Drenagem Urbana. Contudo, a gestão dos planos específicos de bacias hidrográficas é gerida pela Secretaria Municipal de Infraestrutura Urbana e Obras - SIURB, sendo contratados de acordo com prioridades que nem sempre coincidem com as definidas pela Secretaria Municipal de Desenvolvimento Urbano - SMDU e desenvolvidos sem coordenação entre elas.

Os planos de macrodrenagem deveriam servir de base para o detalhamento do PDE na escala dos bairros, ou seja, nos Planos Regionais, o que não acontece. Resulta em um descompasso que impede que a construção dos instrumentos que definem o uso e ocupação do solo (Zoneamento, Planos Regionais, Planos de Intervenção Urbana, Área de Estruturação Local) considerem as condições objetivas das bacias hidrográficas e suas áreas de risco. Desse modo, o combate às enchentes se torna estritamente uma ação de infraestrutura de caráter corretivo estritamente setorial, sem poder se aproveitar de instrumentos urbanísticos de caráter preventivo ou não-estrutural.

Os sistemas de drenagem urbana desenvolvidos a partir dos anos 1990, tais como Low Impact Development LID, Water Sensitive Urban Design WSUD e Sustainable Drainage Systems SuDS estabelecem a integração da drenagem e outras redes de infraestrutura com o planejamento e projeto urbano, de áreas verdes de lazer.

A partir do início deste século, alguns municípios procuraram incorporar essas abordagens em seus projetos de drenagem. Em 2006 o Ministério das Cidades lançou o programa "Drenagem Urbana Sustentável", incentivando os municípios utilizarem técnicas de LID em seus planos de macrodrenagem. A iniciativa não obteve sucesso, e permanecem as práticas de aceleração da vazão através da canalização em concreto armado e da retenção obtida através de grandes "piscinões". Souza, Cruz e Tucci (2012), acusam a falta de capacidade gerencial para a aproximação de diferentes campos de atuação do poder executivo como responsável pelo insucesso.

Travassos e Schult (2013) analisam detalhadamente as dificuldades de ação integrada de secretarias municipais de São Paulo, na articulação de programas com o objetivo de "dar espaço para o rio respirar", uma diretriz básica dessas novas concepções de macrodrenagem do Plano Diretor Estratégico de 2002. No artigo 106, o PDE 2002 criou a Rede Hídrica Estrutural, enfatizando o papel múltiplo dos fundos de vales para drenagem, lazer e meio ambiente. Para sua implementação, estabeleceu a utilização do instrumento urbanístico Áreas de Intervenção Urbana - AIU (inciso VI do artigo 146) "porções do território de especial interesse para o desenvolvimento urbano, objeto de projetos urbanísticos específicos, nas quais poderão ser aplicados instrumentos de intervenção, previstos na Lei Federal $\mathrm{n}^{0}$ 10.257, de 10 de julho de 2001 - Estatuto da Cidade, para fins de regularização fundiária, execução de programas 


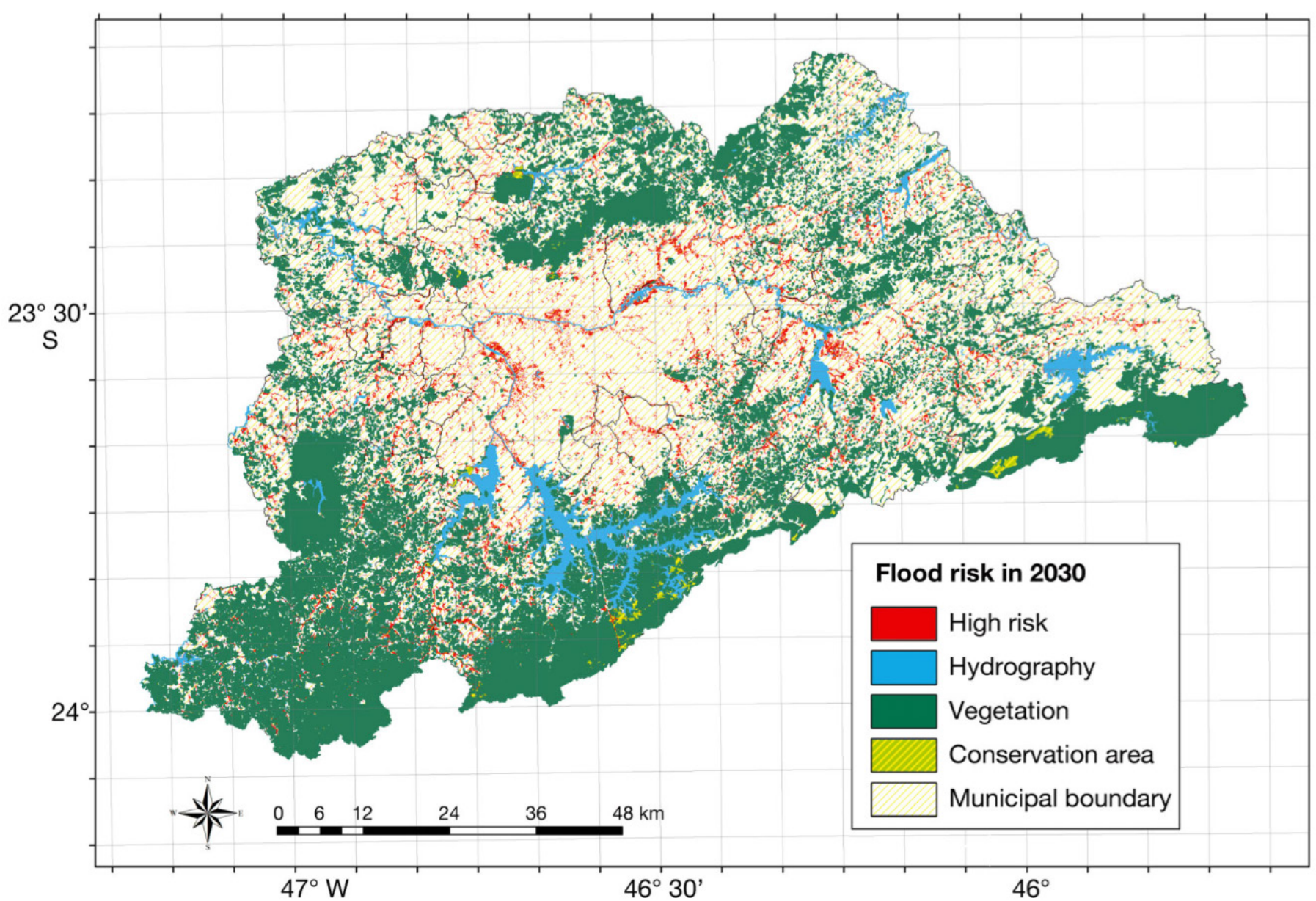

Fig. 4. Simulação da expansão da ocupação urbana na Região Metropolitana de São Paulo (YOUNG, 2013).

e projetos habitacionais de interesse social, constituição de reserva fundiária, ordenamento e direcionamento da expansão urbana, implantação de equipamentos urbanos e comunitários, criação de espaços públicos de lazer e áreas verdes, criação de unidades de conservação ou proteção de outras áreas de interesse ambiental"

Travassos e Schult (2013) demonstram que mesmo dotadas de instrumentos legais, as gestões municipais seguintes não foram capazes de articular as ações de saneamento (programa Córrego Limpo), com a criação do sistema de parques lineares junto aos rios (programa "100 Parques em São Paulo"), e com a necessária remoção e alocação de domicílios em áreas de risco (Plano Municipal de Habitação). Os dois artigos indicam que os limites de gestão são preponderantes frente aos limites técnicos, e que são recorrentes desde o PDE 2002, no mínimo.

Destaque-se a experiência de Porto Alegre nesse período, que realizou seu Plano Diretor de Drenagem Urbana (2003) com abordagem integrada. A partir dele, o Plano de Drenagem Urbana do Arroio do
Moinho introduziu a estratégia de distribuição de pequenas retenções em praças e equipamentos públicos, de baixo impacto urbano, mas capazes de evitar as enchentes na própria sub-bacia e na bacia à jusante.

Aprovado em julho de 2014, o PDE desdobrou-se na nova Lei de Zoneamento, como é popularmente conhecida a Lei de Parcelamento, Uso e Ocupação do Solo LPUOS (2015), Planos Regionais (2016) e no Código de Obras (2016), os quais formaram um conjunto de leis em vigor, que vem regulamentando o desenvolvimento urbano da cidade de São Paulo nos últimos quatro anos.

Dois estudos realizados após a aprovação dessas quatro leis simulam os efeitos do adensamento previsto nos Eixos de Estruturação da Transformação Urbana.

No primeiro, na área de clima, simula seu impacto na distribuição de chuvas em função dos diferentes cenários de crescimento urbano. O outro, da engenharia hidráulica, avalia a impermeabilização do solo estabelecido na nova legislação urbana e 


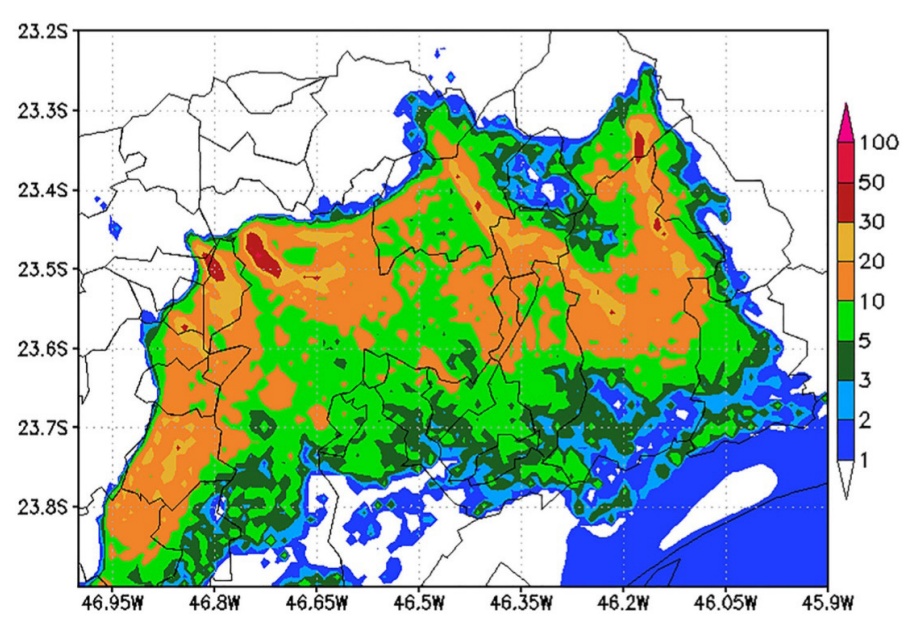

Fig. 5. Experimento 2 de simulação da precipitação sobre a expansão da ocupação urbana realizada por Young, 2013 (BENDER et al, 2019).

seu efeito para a drenagem.

\section{Expansão urbana e clima}

Com o objetivo de entender o impacto da forma urbana no comportamento do clima, em especial das chuvas intensas, Bender, Freitas e Machado (2019) compararam o comportamento de uma chuva ocorrida em São Paulo em 14 de fevereiro de 2013, com dois cenários possíveis para 2030. Um apoiado na continuidade da taxa de crescimento registrada entre 2001 e 2008, outro simulando a aplicação dos parâmetros de contenção da expansão horizontal estabelecidos pelo Plano Diretor Estratégico.

O primeiro cenário foi criado pela simulação da expansão da ocupação urbana na RMSP para 2030 (YOUNG, 2013), realizada a partir de dados do Landsat TM7 utilizando o software Dinâmica EGO, mostra um cenário alarmante de aumento de 38,7\%. Sobre esse cenário, o estudo é muito importante, pois avança em identificar uma ampliação das áreas suscetíveis a deslizamentos em 2008, de 0,9\% para 4,27\% em 2030. O exame amostral dos mapas gerados pela pesquisa, contudo, sugere a necessidade de confrontá-los com outras escalas de análise, de modo a validar os resultados e a metodologia adotada. Como a simulação de Young foi feita em paralelo à elaboração do PDE 2014, não foram nele incorporadas as suas diretrizes de redistribuição do adensamento.

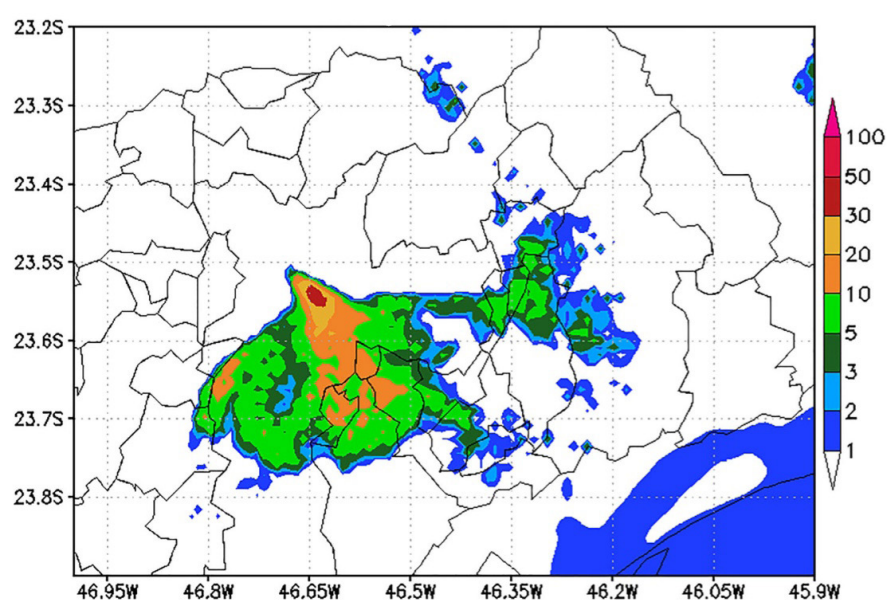

Fig. 6. Experimento 3 de simulação da precipitação sobre a expansão da ocupação urbana proposta pelo PDE 2014 (BENDER et al, 2019).

Nesse sentido a abordagem de Bender, Freitas e Machado (2019) traz importante contribuição de método, pois simulam a cidade gerada pelos , as diretrizes de adensamento linear do PDE, com maior altura dos edifícios, para estudar seu impacto na distribuição de chuvas na RMSP, comparando-a com os efeitos do cenário criado por Young.

O resultado do estudo demonstra que as estratégias urbanísticas propostas no zoneamento do PDE alteram significativamente a tendência "espontânea" de espraiamento do crescimento estabelecida por Young.

Define assim quatro experimentos. O primeiro, para validação do modelo, foi o da própria tempestade ocorrida em 2014 na cidade existente na época. Os dois seguintes puderam comparar as duas simulações da área urbana em 2030. O quarto experimento previu a distribuição dos edifícios mais altos em toda a área de urbanização prevista por Young, o que resultado de um hipotético descontrole total desse processo.

Enquanto experimento 2, sobre o estudo de Young, mostra a um aumento de volume da precipitação, distribuída por toda a área densamente urbanizada da RMSP, em especial na Zona Leste, o experimento 3, sobre a simulação de Bender, indica um menor volume de precipitação, concentrado nas áreas mais verticalizadas do Centro e na Zona Sul da cidade de São Paulo.

No experimento 2, o maior volume de chuva decorre do aumento da temperatura na superfície, 


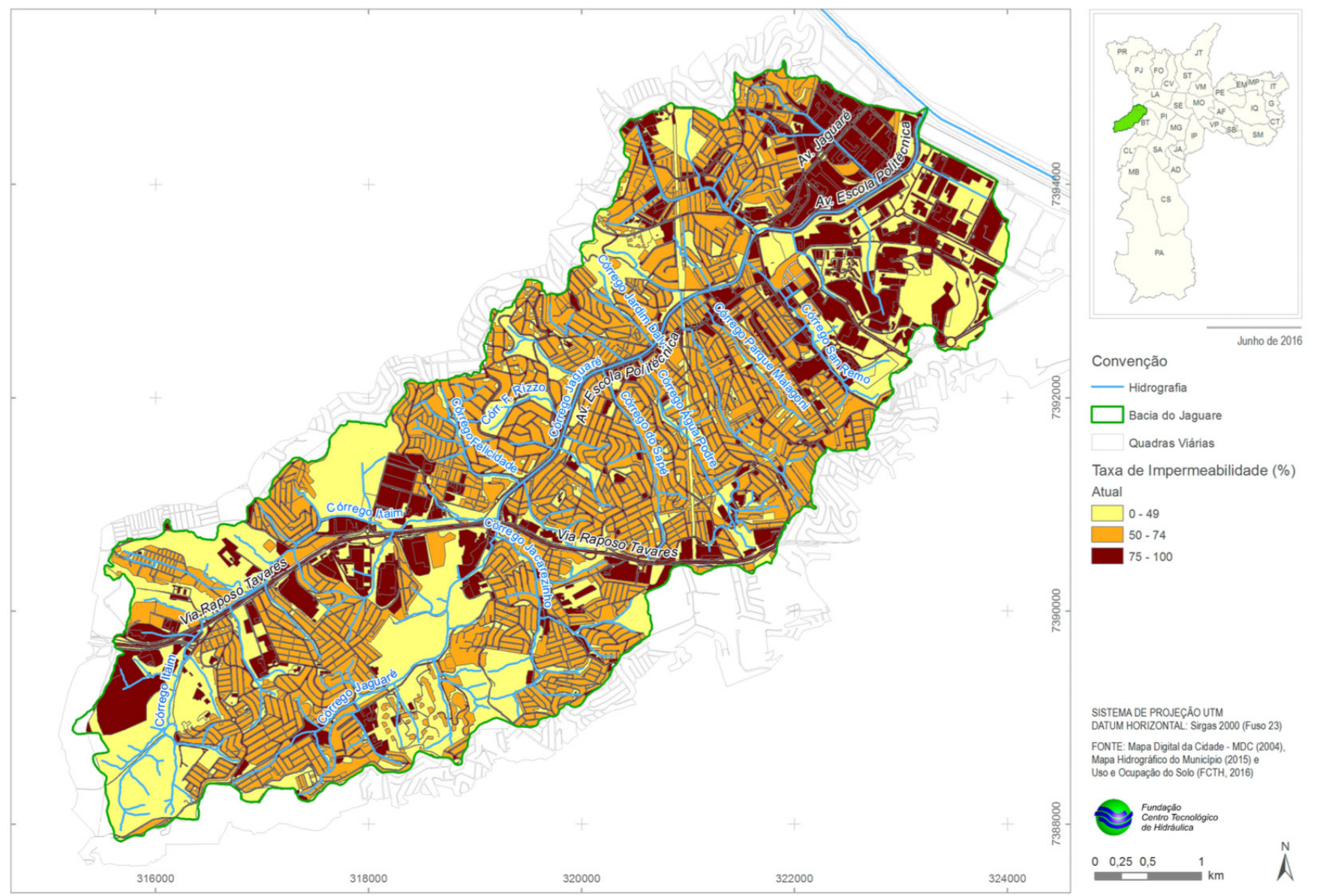

Fig. 7. Taxa de impermeabilização da bacia do Jaguaré atual (Caderno FCTH, 2016).

onde ocorre a remoção da vegetação para a urbanização. A redução do volume de chuva no experimento 3 decorre da redução da temperatura na superfície do solo em função da maior altura dos edifícios, que também são responsáveis pelo desvio das brisas do mar das áreas centrais mais quentes, que passariam por sobre a área urbana em direção norte.

Essa diferença tem impacto regional na distribuição das chuvas que garantem o abastecimento de água potável para a RMSP. A menor precipitação na RMSP significa que o ar úmido vindo do oceano consegue ultrapassá-la e chegar aos reservatórios do sistema Cantareira, situados a norte. Os cenários urbanos dos outros três experimentos explicam como a forma da área urbanizada, extensa e horizontal, força a precipitação precoce das brisas úmidas marítimas sobre a cidade, causando enchentes ao mesmo tempo que deixa de recarregar os reservatórios do sistema Cantareira, levando à escassez de água potável.

\section{Engenharia hidráulica e urbanismo}

Os cadernos de bacia hidrográfica elaborados pela Fundação Centro Tecnológico de Hidráulica FCTH para a Secretaria Municipal de Infraestrutura e Obras Siurb realizam o diagnóstico da bacia e apresentam propostas para combate às enchentes. Apesar da gravidade das enchentes no município, estão disponíveis para consulta os cadernos de apenas 6 bacias $^{1}$, sendo que somente 3 englobam grandes áreas de EETU ao longo do córrego.

Os cadernos são básicos para a tomada de decisão pela prefeitura sobre quais projetos de dispositivos serão desenvolvidos. A priorização é feita pela SIURB, que tem seus critérios independentes da SMDU e SP Urbanismo, responsáveis pela aplicação das diretrizes do PDE.

1 Cabuçú de Baixo (ZEU e ZEIS), Jacú (ZEU e OU), Morro do $S$ (ZEU, ZEIS, ZM). ). Águas Espraiadas tem uma ZEU nas cabeceiras, mas é predominantemente ZER_1, ZC e ZM. As demais são Jaguaré (ZC, ZM e ZOE - USP), Mandaqui (ZM e ZC). Há informações de que mais cinco cadernos estão concluídos e serão divulgados ainda em 2020 - córregos Sumaré, Água Preta, Uberaba, Pirajuçara e Aricanduva. Estão contratados os cadernos de drenagem dos córregos Verde (Pinheiros), Anhangabaú, Tiquatira, Itaquera, Tremembé e CEAGESP. 


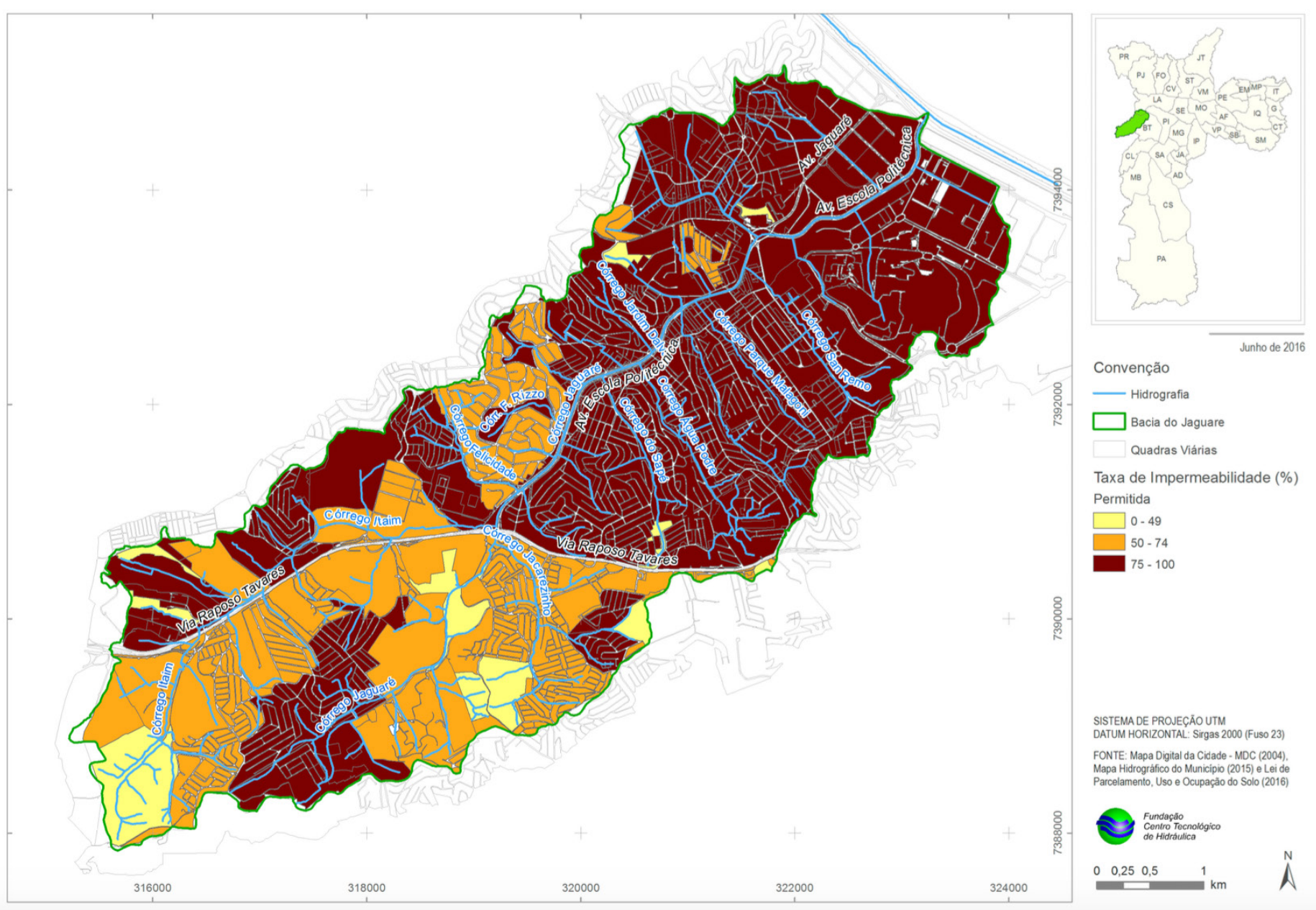

Fig. 8. Taxa de impermeabilização da bacia do Jaguaré futura (Caderno FCTH, 2016).

O método aplicado pela FCTH é o do Departamento de Agricultura dos Estados Unidos, o Natural Resources Conservation Service (NRCS), no qual várias características da urbanização geram fatores para o cálculo do volume de vazão. As variações do uso e ocupação do solo determinam as taxas de impermeabilização e os índices de escoamento. Quanto mais o solo é coberto por revestimentos impermeáveis - pavimentos e construções, menor a permeabilidade e maior o excedente de água que corre para o exutório. A taxa de impermeabilização atual é estimada a partir dos levantamentos do existente, enquanto para as taxas futuras, a FCTH utilizou a Lei de Parcelamento, Uso e Ocupação do Solo - LPUOS. Nela estão definidas as taxas de permeabilidade mínima para as futuras construções por tamanho do lote, que é de 15\% em lotes menores de $500 \mathrm{~m}^{2}$, e $25 \%$ nos maiores. Para efeito de cálculo, os cadernos consideram um horizonte de ocupação máxima dentro desses limites. Contudo, a impermeabilização da bacia atual não atinge o máximo do permitido pela legislação anterior. Quando comparadas, a evolução na impermeabilização das bacias estudadas é alarmante.

As limitações da comparação precisam ser mais bem avaliadas, em especial se considerarmos os ritmos passados de crescimento da cidade, como fez Young em sua simulação para 2030, usando uma média da expansão urbana entre 2001 e 2008. São claros os efeitos de distorções da simulação da taxa de impermeabilização futura no dimensionamento, planejamento e distribuição de dispositivos de combate à enchente, as quais influem diretamente na tomada de decisões na definição das prioridades.

O cálculo da impermeabilização pelo máximo da ocupação desconsidera ainda os instrumentos urbanísticos do PDE e da LPUOS, previstos para serem usados para atenuar a o crescimento excessivo do volume de vazão de águas pluviais, tais como a Quota Ambiental e os Projetos de Intervenção Urbana em terrenos de grande área. 


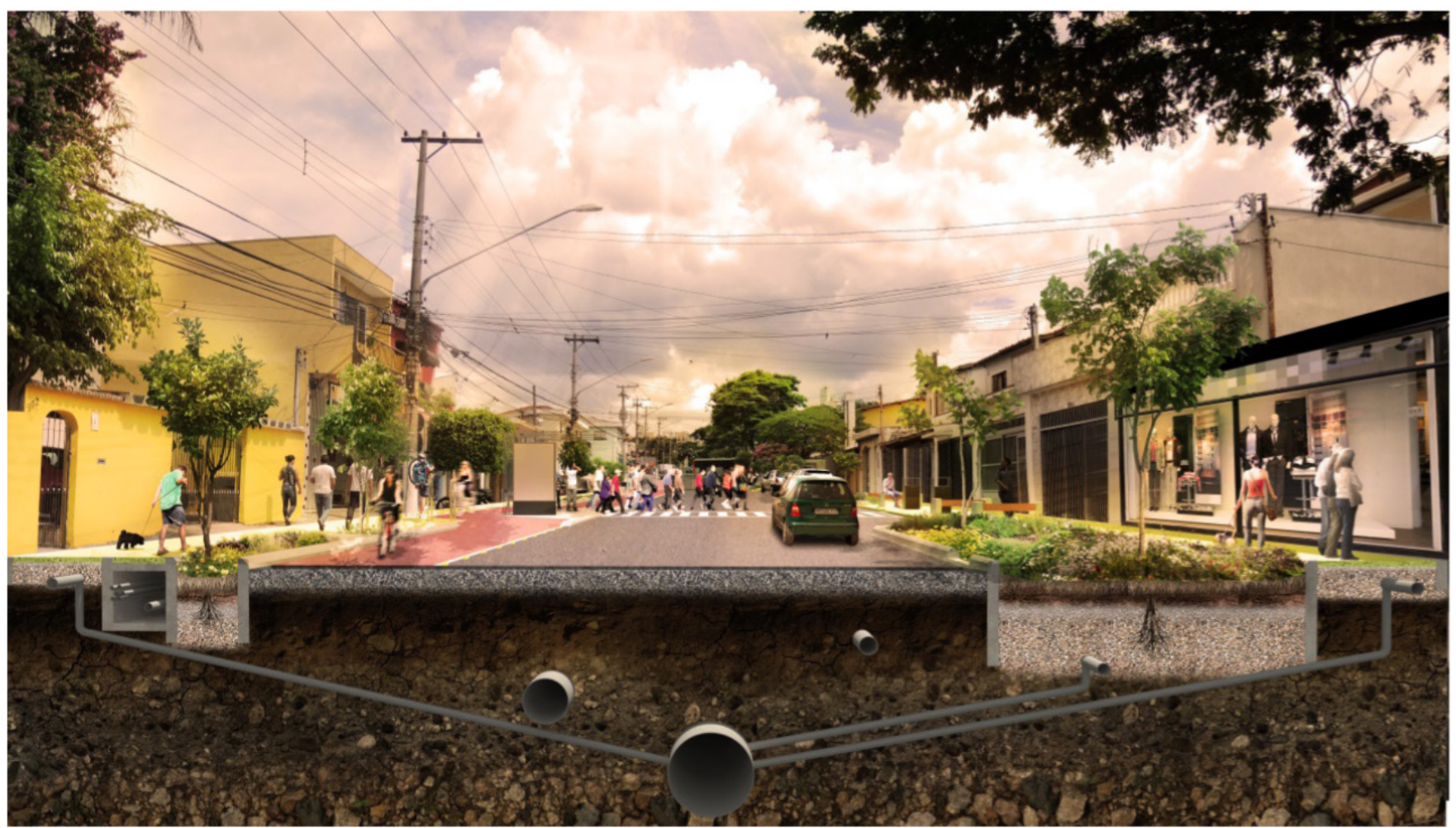

Fig. 9. Corte esquemático de rua adaptada com dispositivos LID (MARQUES et al, 2018).

A descoordenação entre o setor de infraestrutura e o de urbanismo manifesta-se desde a escolha das bacias a serem estudadas, até nos critérios adotados no estudo. Repetem-se os problemas do período de 2005 a 2012 que comprometeram a implantação dos parques lineares, conforme já apontado por Travassos e Schult (2013).

\section{Novos paradigmas técnicos e seus limites frente a realidade urbana/ambiental de São Paulo}

Os seis cadernos de bacia hidrográfica disponibilizados em 2016 apresentam um amplo leque de opções técnicas no projeto de dispositivos de prevenção de enchentes, incorporando parques lineares com função de amortecimento e acomodação das cheias. Fica claro o esforço da engenharia hidráulica, liderado pela FCTH (Poli USP) em parceria com o LabVerde (FAU USP), em introduzir alternativas ao paradigma técnico dos parques lineares e retenções, introduzindo parâmetros de infraestrutura verde no lugar das canalizações com paredes de concreto armado cruzando áreas verdes².

2 Técnica usada na primeira geração de parques lineares, que tem no Parque Tiquatira (2008), na Zona Leste, seu maior exemplo.
Os estudos realizados no Projeto Jaguaré ${ }^{3}$ dentro do plano de despoluição do Rio Pinheiros (MARQUES et al: 2018), incorpora princípios de LID associados aos de Infraestrutura Verde. Os estudos não se limitam às proximidades do curso d'água no fundo de vale, distribuindo dispositivos por toda a bacia. Os LIDs do tipo jardim de chuva, canteiro pluvial e pavimento permeável são propostos para espaços abertos ao longo de vias públicas e edifícios. Ampliam os dispositivos propostos para os parques lineares, criando uma rede "multifuncional e interconectada", associada a grandes bacias de detenção e retenção também concebidas com infraestrutura verde. Segundo Marques (2018:20), tais bacias teriam a função de amortecer os impactos de chuvas com tempo de recorrência de 100 anos, podendo assim ter uso paisagístico. Trata-se de uma linha de investigação consistente e inovadora, que enfrenta o desafio de associar as LID e as Infraestrutura Verde às condições reais da cidade brasileira.

Uma outra linha de investigação, associada aos instrumentos urbanísticos e diretrizes do PDE, vem 3 Projeto realizado entre dezembro/2015 e julho/2017 em articulação com a "Associação Águas Claras do Rio Pinheiros", sob a coordenação técnica da Fundação Centro Tecnológico de Hidráulica (FCTH), com a participação do Labverde (FAUUSP) e financiamento do Fundo Estadual de Recursos Hídricos (FEHIDRO). 


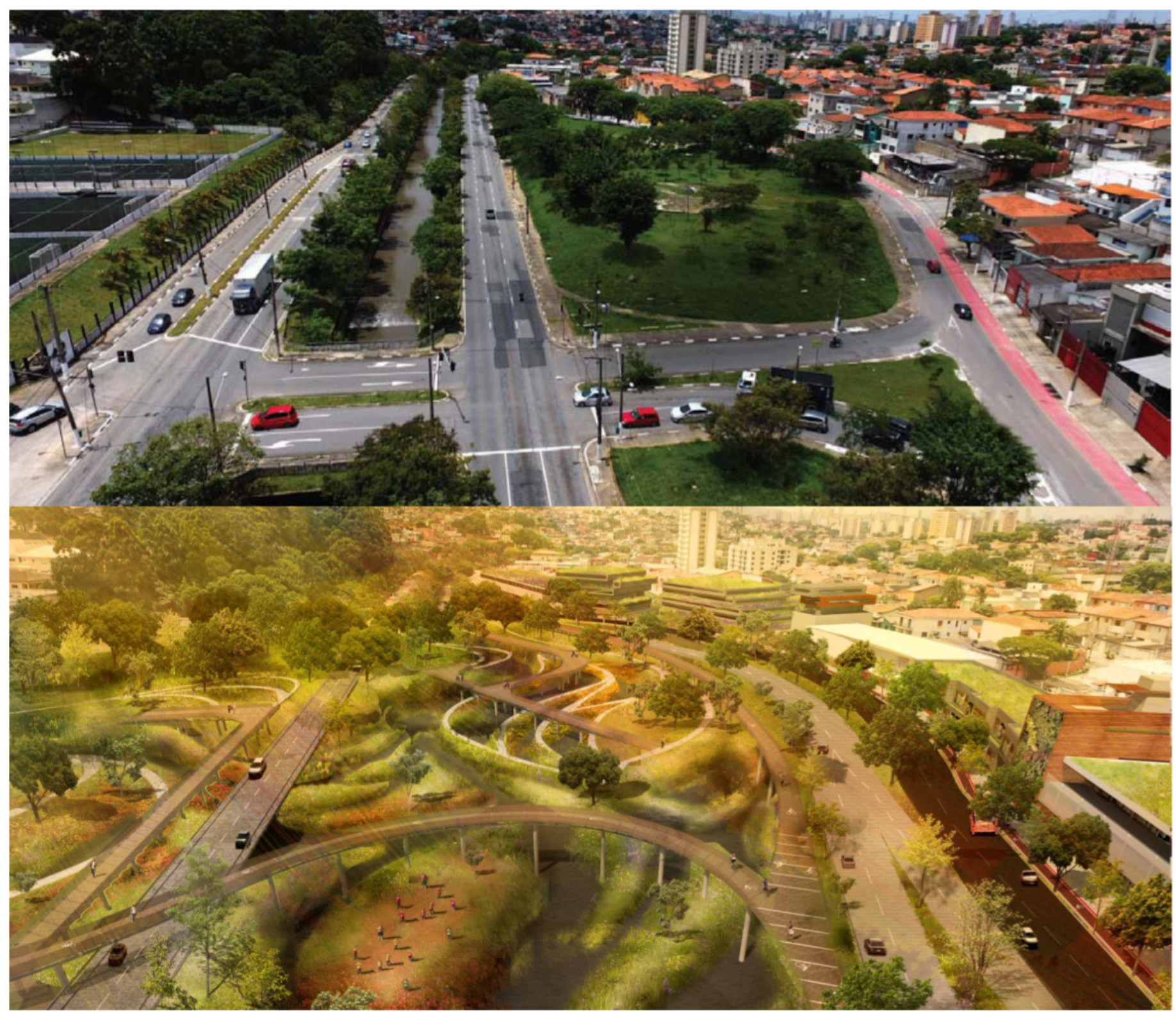

Fig. 10. Projeto de dispositivo de retenção de cheias na bacia do Jaguaré (MARQUES et al, 2018).

sendo desenvolvida sob coordenação deste autor. Os dois estudos de caso realizados estão associados a fundos de vale ocupado (ou a ser ocupado) por corredor de ônibus, fazendo parte de um EETU.

Durante o período de revisão do PDE e elaboração da LPUOS, em 2014, pesquisadores e estudantes do Instituto de Arquitetura e Urbanismo e Escola de Engenharia de São Carlos realizaram estudos urbano-ambientais em duas bacias na periferia de São Paulo, a do Lageado, Zona Leste e a do Cabuçú de Baixo, Zona Norte. Como ambas as bacias escolhidas não possuíam estudos hidrológicos de drenagem na época, o enfoque desses trabalhos foi o de analisar os conflitos entre as redes de infraestrutura e as condições urbanas existentes, procurando nos instrumentos urbanísticos do PDE possibilidades de diretrizes para projetos locais.

A bacia do córrego do Lageado abrange duas subprefeituras, Itaim Paulista e Guaianases, tendo suas cabeceiras no município Ferraz de Vasconcelos. De acordo com o PDE, a região receberia um corredor de ônibus ao longo da avenida Dom João Neri, a qual segue próxima ao curso d'água, mas fora da sua Área de Preservação Permanente. O problema colocado foi o de aproveitar o EETU proposto para acompanhar o corredor de ônibus e conceber um processo de renovação urbana que integrasse a infraestrutura viária ao plano de drenagem, incorporando o reassentamento dos moradores de áreas de risco e a criação de um corredor verde.

Para isso foi criado o Corredor Ambiental Urbano, 


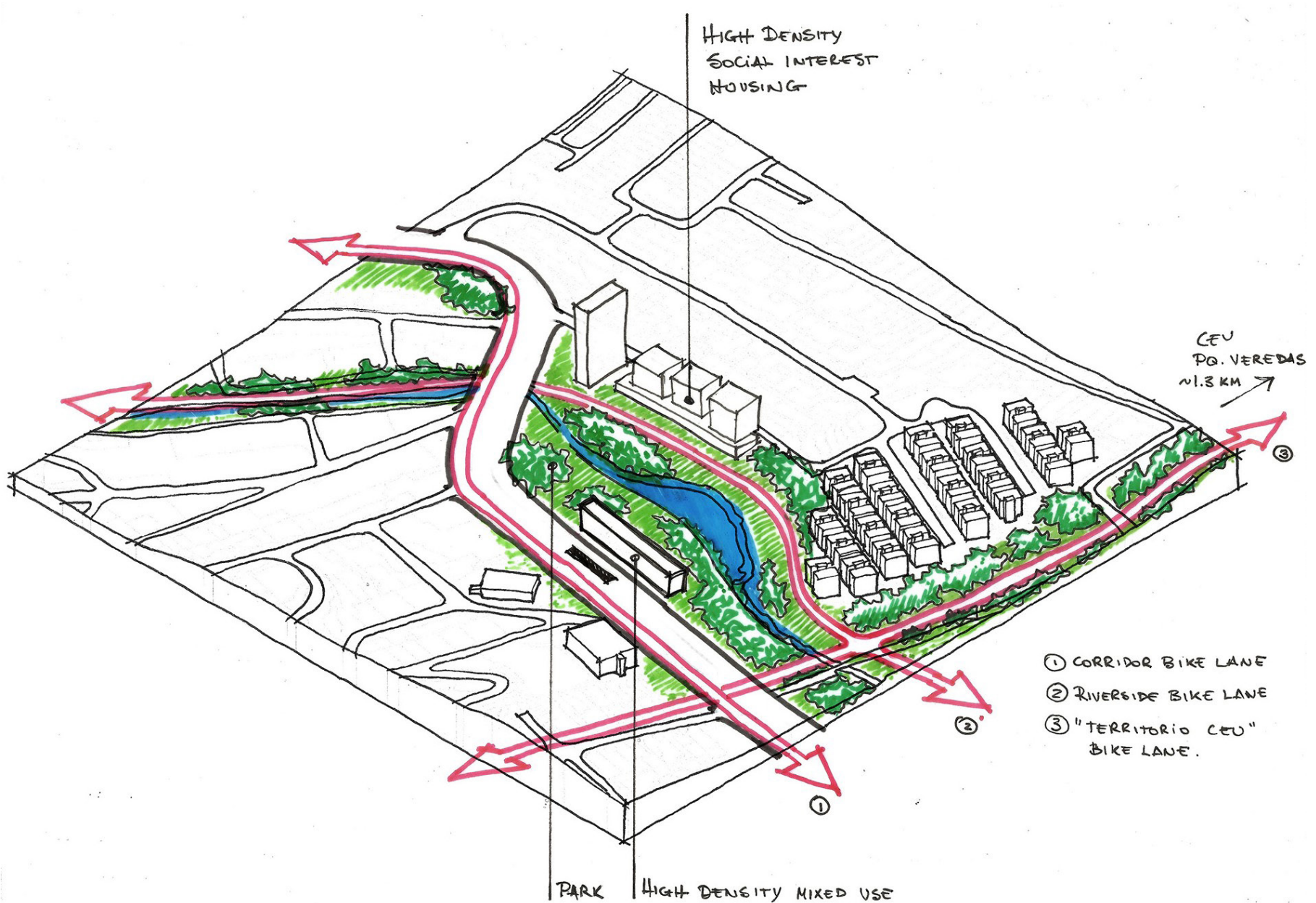

Fig. 11. Corredor Ambiental Urbano na bacia do Lageado, Itaim Paulista (ANELLI; LEITÃO, 2014).

um modelo referencial desenvolvido no workshop "Estudos Urbanos SP: novas linhas de mobilidade" (ANELLI; SANTOS, 2014), promovido em março de 2014 pelo IAU USP em parceria com a HCU Hamburgo, Engenharia Ambiental da EESC USP e SMDU de São Paulo 4 .

Ainda no mesmo ano, durante o segundo semestre, foi promovida pela SMDU os Ateliers Ensaios Urbanos, reunindo estudantes e professores de 17 instituições de ensino de Arquitetura e Urbanismo. Entre os projetos desenvolvidos pelas equipes do IAU USP, destaque-se, para este tema, o estudo para a bacia do Cabuçú de Baixo, distribuída nas subprefeituras Freguesia - Brasilândia e Casa Verde - Cachoeirinha ${ }^{5}$.

4 Estudos Urbanos SP: novas linhas de mobilidade. Workshop promovido em março de 2014 sob a coordenação deste pesquisador, faz parte da colaboração entre o Instituto de Arquitetura e Urbanismo da Universidade de São Paulo e a HafenCity Universität de Hamburgo com participação da Engenharia Ambiental da Escola de Engenharia de São Carlos da Universidade de São Paulo e da Secretaria Municipal de Desenvolvimento Urbano de São Paulo. O workshop teve o patrocínio do Centro Alemão de Ciência e Inovação de São Paulo.

5 Composição da equipe.
A avenida Inajar de Souza, onde se localiza o corredor de ônibus, situa-se às margens de canal de concreto armado, sem nenhum afastamento. O estudo propôs um conjunto de regras de remembramentos de lotes e instrumentos para regulação visando a abertura de espaços dentro dos quarteirões para o acolhimento de dispositivos de drenagem.

As estratégias dos dois estudos são complementares. Ações concentradas nos fundos de vale e distribuídas pelas encostas da bacia devem ser concebidas dentro de um mesmo sistema integrado.

O caso da bacia do Lageado no Itaim Paulista teve desdobramentos de pesquisa nos anos seguintes. Em 2015 a USJT passou a participar da pesquisa através da professora Ana Paula Koury, que criou o Lab Itaim Paulista com professores e estudantes de arquitetura, urbanismo e engenharia civil, muitos deles moradores da região. O Lab Itaim Paulista é um laboratório de transformação urbana e planejamento local, que pretende contribuir 


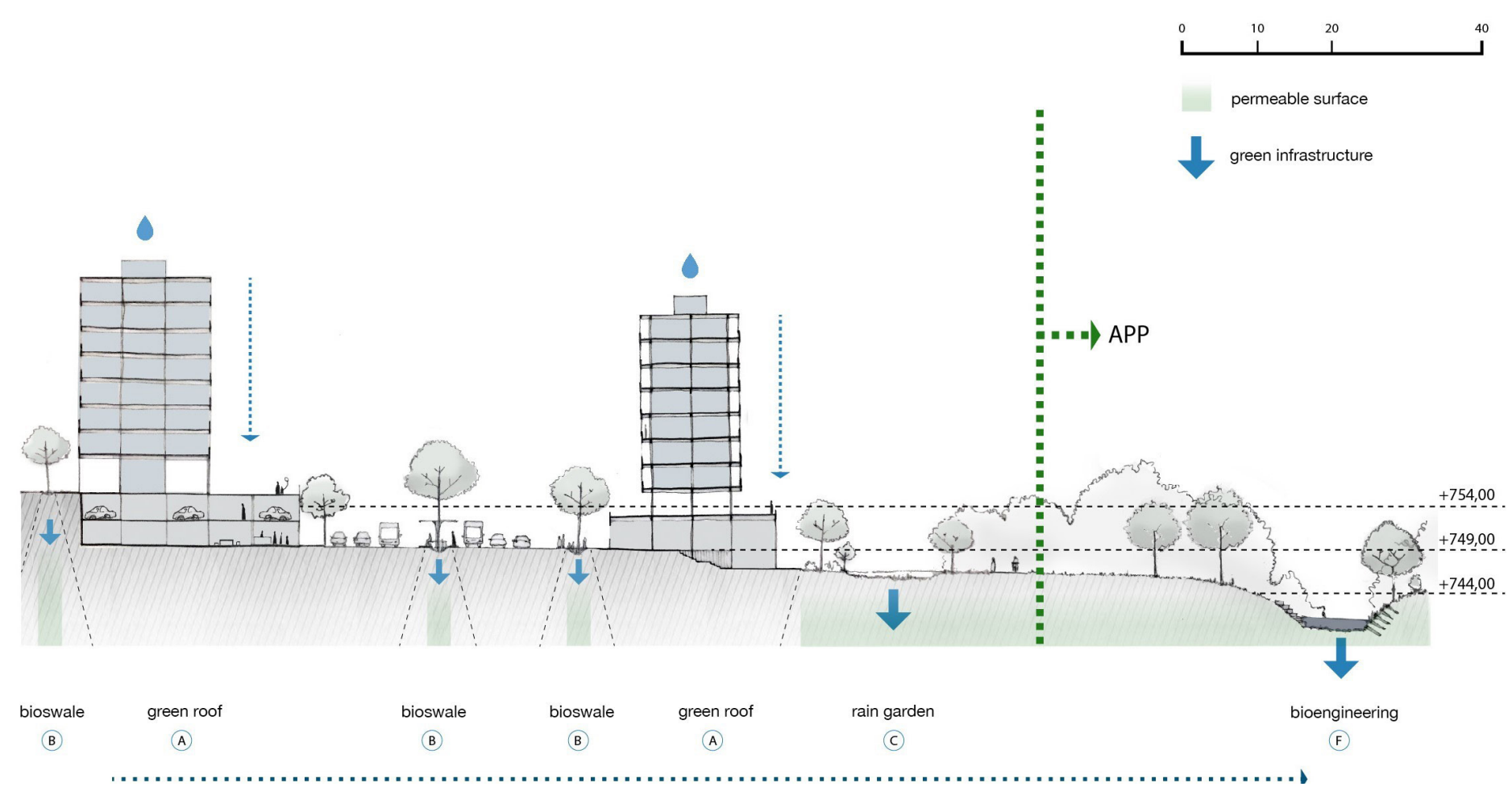

Fig. 12. Plano de drenagem LID na bacia do Lageado, Itaim Paulista (KAZAKU, 2016).

para a integração entre as diferentes escalas de administração da cidade, com o objetivo de melhorar a governança em uma das áreas mais vulneráveis do Município de São Paulo. Através de convênio com a subprefeitura do Itaim Paulista, professores e estudantes contam com uma inserção local permanente, que Ihes permite aprofundar os estudos do aumento da vulnerabilidade urbana da região frente às mudanças climáticas.

\section{Conclusões}

Avaliar a relação entre mudanças climáticas e cidades exige os dois caminhos discutidos aqui. 0 primeiro é entender a urbanização como um forte agente promotor do aquecimento do clima, e no sentido inverso, os efeitos das mudanças climáticas sobre cidades marcadas pela desigualdade social de seus assentamentos. Ao mesmo tempo promotora do aquecimento e vítima dos seus efeitos, as cidades precisam mudar para sobreviver. O trânsito entre os conhecimentos das ciências básicas, ciências ambientais, ciências sociais, engenharias, urbanismo, arquitetura, gestão urbana, entre outras, deve ser propiciado pelo ensino e pesquisa nas universidades que pretendem desempenhar um papel ativo na construção de novos paradigmas de sustentabilidade ambiental. Este artigo introduz um ponto de vista para tal construção.

\section{Referências bibliográficas}

ANELLI, R. L. S.; SANTOS, A. L. Corredores ambientais urbanos: desafios para o desenvolvimento do Plano Diretor Estratégico de São Paulo, articulando as escalas metropolitana, regional e local. In: III ENANPARQ Arquitetura, Cidade e Projeto: uma Construção Coletiva. São Paulo, 2014.

BENDER, A.; FREITAS, E. D.; MACHADO, L. A. T. The impact of future urban scenarios on a severe weather case in the metropolitan area of São Paulo.

Climatic Change, v. 156, p. 471-488, 2019.

CANHOLI, A. P. Drenagem urbana e controle de enchentes. São Paulo: Oficina de Textos. 2005.

FCTH. Desenvolvimento de metodologia e projeto piloto de revitalização de bacia urbana, replicável para as demais bacias da região metropolitana (Bacia do Córrego Jaguaré), Empreendimento 2014 AT-653. Volumes I, II, III e IV, 2017.

FERREIRA, L. S. Vegetação, temperatura de 
superfície e morfologia urbana: um retrato da região metropolitana de São Paulo. Tese (Doutorado em Arquitetura e Urbanismo) Faculdade de Arquitetura e Urbanismo da Universidade de São Paulo. 2019.

FERREIRA, L. S. R.; DUARTE, D. Exploring the relationship between urban form, land surface temperature and vegetation indices in a subtropical megacity. Urban Climate, v. 27, p. 105-123, 2019.

GROSTEIN, M. D. Metrópole e expansão urbana: a persistência de processos "insustentáveis". São Paulo Perspec., São Paulo , v. 15, n. 1, p. 13-19, Jan. 2001.

KAKAZU, P. E. A água como disparador de projeto urbanístico. Pesquisa de Iniciação Científica, bolsa CNPa, Instituto de Arquitetura e Urbanismo, Universidade de São Paulo, São Carlos, 2016.

KOURY, A.; CAVALLARI, T. Desenvolvimento urbano em áreas de fronteira: o caso do Itaim Paulista. Urbe Revista Brasileira de Gestão Urbana, v. 10, n. 1, p. 663-676, 2018.

MARQUES, T. H. N. et al. Projeto Jaguaré: Metodologia para requalificação de bacias hidrográficas urbanas.

Revista eletrônica LABVERDE, n. 9, p. 12, 2018.

NOBRE, C. et al. Vulnerability of Brazilian Megacities to Climate Change: the São Paulo Metropolitan Region (RMSP). In: MOTTA, R.S. et al (Eds). Climate Change in Brazil: economic, social and regularoty aspects. Brasília: IPEA, 2011, p. 197-219.

ROSENZWEIG, C.; SOLECKI, W. Action pathways for transforming cities. Nature Climate Change, v. 8, p. 756-759, 2018. apud MARENGO, J.A. et al. Trends in extreme rainfall and hydrogeometeorological disasters in the Metropolitan Area of São Paulo: a review. Annals of the New York Academy of Sciences, v. 1452, p. 1-16, 2020.

SILVA DIAS, M. A. F. et al. Changes in extreme daily rainfall for São Paulo, Brazil. Climatic Change, v. 116, p. 705-722, 2013.
SOUZA, C. F.; CRUZ, M. A.; TUCCI, C. E. M. Desenvolvimento Urbano de Baixo Impacto: Planejamento e Tecnologias Verdes para a Sustentabilidade das Águas Urbanas. Revista Brasileira de Recursos Hídricos, v. 17, n. 2, p. 9-18, 2012.

STEWART, I. D.; OKE, T. R. Local climate zones for urban temperature studies. Bulletin of the American Meteorological Society, v. 93, n. 12, p. 1879-1900, 2012.

TRAVASSOS, L. R. F. C. Revelando os rios: novos paradigmas para a intervenção em fundos de vale urbanos na Cidade de São Paulo. 2010. Tese (Doutorado em Ciência Ambiental) - Ciência Ambiental, Universidade de São Paulo, São Paulo, 2010.

TRAVASSOS, L.; SCHULT, S.I.M. Recuperação socioambiental de fundos de vale urbanos na cidade de São Paulo, entre transformações e permanências. Cadernos da Metrópole, v. 15, n. 29, p. 289-312, 2013.

YOUNG, A. Urban expansion and environmental risk in the São Paulo Metropolitan Area. Climate Research, v. 57, p. 73-80, 2013. 